Jurnal Pendidikan IPA Indonesia

\title{
DESIGN OF LEARNING MEDIA: MODELING \& SIMULATION OF BUILDING THERMAL COMFORT OPTIMIZATION SYSTEM IN BUILDING PHYSICS COURSE
}

\author{
E. K. Wati ${ }^{* 1}$ and N. Widiansyah ${ }^{2}$ \\ 1,2Department of Physics Engineering, Universitas Nasional, Jakarta Selatan, Indonesia
}

DOI: 10.15294/jpii.v9i2.23504

Accepted: February $20^{\text {th }} 2020$. Approved: June $25^{\text {th }} 2020$. Published: June $30^{\text {th }} 2020$

\begin{abstract}
The use of instructional media is something that can support the teaching and learning process; therefore, a lecturer must have the ability to create and develop learning media. This study aims to improve student learning outcomes in building physics course by using simulation learning media and models to help students understand thermal comfort material. Making modelling and simulation media is done using MATLAB software. The subjects of this study were physics engineering students who took Building Physics course. At the beginning of the study, students are given material and then in groups discuss thermal contents and then given a pretest test with an average score of 70.27, and for an average grade of 71.3 assignments. At the meeting next week, using the Student-Centered Learning (SCL) method and using problem-based learning in groups, students take temperature measurements in several rooms in the Building at the UNAS Physical Engineering Laboratory. The measurement results show that the room does not have thermal requirements (PERGUB No. 38/2012), so students have the task of conducting experiments using models that have been created by researchers to create learning media to improve comfort in using thermal buildings. Simulation results carried out by students, that is, can produce rooms with thermal conditions at $21-25^{\circ} \mathrm{C}$ (PERGUB No. 38/2012). This simulation is also able to provide the score of building energy efficiency. After students succeed in conducting the test, the assessment test or posttest is carried out with an average score obtained 80.55, and an average score of 80 assignments. The results of the pretest, assignment 1 , assignment 2 , and posttest show an increase in students' scores of $14.6 \%$ for the Test and Task Score of $12.20 \%$. Based on the hypothesis test, for both variables showed $t$-count $<\mathrm{t}$-table and significance $<0.05$. It shows there are significant differences in student learning outcomes both test scores and assignment scores before and after using a simulated media. Thus, the system and simulation model designed can be used as learning media that can improve student learning outcomes.
\end{abstract}

(C) 2020 Science Education Study Program FMIPA UNNES Semarang

Keywords: learning media; simulation; thermal condition

\section{INTRODUCTION}

So far, there are still many learning physics using the lecture method (TCL), and some lecturers still think about students having to learn basic concepts using mathematical formulas. Teacher-Centered Learning Methods in universities are no longer applicable. In De Jong et al. (2013) research, the TCL method makes students pas-

*Correspondence Address

E-mail: ernakusuma.w@gmail.com sive because learning only supports the lecturer. Therefore, it is necessary to change the paradigm about the learning process that must involve students to improve understanding of the concepts and material presented. Students Centered Learning (SCL) methods can encourage and motivate students to actively participate, have critical power, can analyze, and can solve problems (Prima et al., 2018). In the learning process as lecturers, we can use several learning methods to create 
a pleasant learning atmosphere. Thus, we must master various techniques, models, or learning technologies (Smetana \& Bell, 2012).

Throughout technological development, learning methods must change for student learning but must improve the understanding of knowledge. We can use digital technology to convey theories and apply underlying physics to students. Simulation is a program that can be agreed upon or made up of things. In the world of education, the 2011 Horizon Report (Johnson et al., 2011) attracted researchers' attention to emerging. Accessible technologies facilitating better learning where the real and digital world lives with the help of real-time (Johnson et al., 2011; Bronack, 2011). In research conducted by Ibáñez et al. (2016) proved that researchers in education support learning with simulation activities (Cheng \& Tsai, 2013).

But on the other hand, there are several uses of computer simulations in learning not effective in improving the process and learning outcomes (Wang et al., 2015; Al-Hmouz et al., 2012). In Schneider et al. (2010) research, in the learning process students are too absorbed in using simulation media, so that much time is wasted in the learning process, resulting in running out of learning time and no time for discussion. So, in the implementation of learning, students focus on understanding the concept of the material, then as lecturers, we must make them work and understand every process or step in the simulation (Aryuntini et al., 2018).

Building physics is a new subject that is opened even semester in 2017 in the department of physics engineering at the national university so that the learning media and equipment facilities in the laboratory are not yet complete if it will apply experimental learning methods and demonstrations (Cukurova et al., 2016) in the laboratory not all content in Building Physics can be practiced immediately remember the limitations of the equipment in the laboratory and time. Thus far, learning has been carried out using traditional methods or lectures. The results of graduation in building physics in 2017 with an average grade of 75.50 or $\mathrm{B}+$. Therefore, we need learning media that can help the material in the physics building course (Jaakkola et al., 2011).

This research aims to improve student learning outcomes in building physics course by applying the student-centered learning method with problem-based learning and to create learning media that helps students understand the concepts of Building Physics better (Luckin et al., 2015). To reduce the problems that occur in
Schneider et al. (2010) research in the learning process with simulation media, this research will use problem-based learning methods to develop students' conceptual understanding (Greiff et al., 2014; Cukurova et al., 2016). Although learning activities take the form of Student-Centered Learning, as lecturers, we must provide assistance consisting of Plan to guide students through the discovery of the process (Requena-Carrión et al., 2010), monitor to help students achieve their progress to support them, and build a process of development to guide students to choose the most relevant and productive tasks (Greiff et al., 2014).

Media design supports system modelling and evaluation to optimize thermal compatibility using MATLAB software. Modelling is done to create a thermal system model by using a mixed system with Performance Coefficient (COP) to make energy efficient. This modelling can provide information for students (Batlolona et al., 2018) on how a more optimal thermal system by using energy more efficiently can save costs incurred in the thermal comfort of buildings. So that it can be used as a learning medium for Building Physics Course and can improve students' understanding of the concept of cooling loads from buildings to determine the most effective capacity of thermal systems, Observe the effect of changes in outdoor temperature and indoor temperatures, Analyze the impacts of changing AC parameters on the air in the room and analyze the performance of the AC controller in keeping the temperature in the comfort range. Thus, students can optimize the thermal comfort of a building (Cukurova et al., 2016).

Modelling and simulation of energy consumption by the thermal system (Guillaud et al., 2015) of a place of residence were studied using MATLAB and Simulink for one year for each day, to model the elements in the building and its thermal system by using a second-order equation, and giving two treatments to the simulation, namely: first, energy consumption is evaluated based on measurements of outdoor temperature per hour on a selected day, and second, energy consumption is estimated based on average outdoor temperature on the same day (Kassas, 2015). In this research, the thermal system will only allow for the energy of the cooling load because the research location is located in a tropical climate country (Indonesia) and does not require a heating system.

The thermal system saving strategy in this study will use a centralized cooling system. This centralized cooling system will use the Air Handling Unit (AHU) as a medium that circulates cold 
airflow from the centralized system. The operational strategy of this thermal system is proven to save more on cooling costs compared to conventional cooling systems in each room (Yang et al., 2017). Research conducted by Budaiwi \& Abdou (2013) concluded that a significant reduction in energy consumption at the mosque could be obtained by maintaining thermal comfort when the air-conditioning system is operated and designed by insulation having a $23 \%$ reduction in cooling energy consumption and at the mosque without insulation 36\%. Wang et al. (2015) conducted a study of thermal systems in classrooms with an assessment of thermal comfort in school buildings using Passive House standards. The results obtained are that the building, as a whole, can meet the Passive House standard that is an energy performance index of less than $15 \mathrm{kWh} /$ (m2day).

This research will use a centralized cooling system with the Air Handling Unit (AHU) as a medium that circulates cold airflow from a centralized system. While the air-conditioning operation time will be carried out continuously as long as the building is actively operating and at night (the building is not operating), the air-conditioning system will be turned off, and cooling will only take advantage of heat escaping through the vents. It is expected that with this treatment, an optimal thermal system model will be obtained. From the thermal system model that will be formed will also be seen the optimal capacity of the air conditioning system, which includes a significant effect on optimizing the cooling energy consumption of a building. Previous studies have observed the impact of excess AC capacity on the required energy consumption.

There are several types of controllers that have been used in modelling thermal systems in previous studies. As in the research conducted by Ardabili et al. (2016), researchers conducted modelling and evaluation of thermal systems with a simple equation of heat exchanger using a Fuzzy controller and RBF network. Based on the results obtained, the predictive control based on the RBF method has a lower stress temperature than the fuzzy system. Other studies conducted by Chen \& Treado (2014) used a PI controller to simulate it. The Trial and error method has been recommended as a PI controller tuning. For energy consumption generated based on simulation results obtained when the reference zone is not filled during the summer, the temperature set point and the position of the dampers reset and shut down the cooling system and can save significant amounts of energy. In the research controller used is a conventional on-off controller. This is done because this type of controller is more comfortable to simulate so that research can focus on optimizing thermal systems based on previous references and predicting the cost and energy consumption resulting from cooling down buildings. On-off controller work cycle graphs and outdoor and indoor temperature graphs for each operating hour will be observed as determining the correctness of the resulting model (Dunn et al., 2011).

\section{METHODS}

The method in the study of the use of simulation-based learning media (Luckin et al., 2015) is to collect information about: curriculum, analysis of students' initial abilities, availability of learning resources, analysis of learning tasks, models and methods of learning, and analysis of the use of learning media (Aryuntini et al., 2018). The subject of this research is Physics Engineering Students, who are taking the Constitutional Physics MK Building Odd School Year $2018 / 2019$. Students get explanatory material about thermal buildings from traditional lecturers (TCL) with a duration of time (Ibáñez et al., 2016). Students are assigned in group to search for research journals related to thermal conditioning in a building. This is to encourage students to look for problems that exist in this study and how to solve them. Furthermore, a pretest is held for the students, carried out for 20 minutes, and 30 minutes for discussion together (Wang et al., 2015). In the following week, students with the same group team (Ahonen et al., 2018) as the previous week were given the task to do thermal and simulation modelling (Batlolona et al., 2018) in the Engineering and Science Faculty Laboratory building located on Bambu Kuning street, Pasar Minggu, South Jakarta.

In the learning process using simulation media, students in groups measure several rooms in the laboratory. Then students will find a problem, namely the thermal conditions of the room that have not been standardized. So based on these problems, the lecturer will give an assignment to students to find solutions (Cukurova et al., 2016) or do optimization to get the term comfort in the room (Vidergor, 2018). With the guidance and direction of the lecturer, students use simulations to perform thermal optimization. During the process of using experimental media, students and lecturers always go around to the process so that learning goes well (RequenaCarrión et al., 2010; Gibson et al., 2014). Finally, students can do thermal optimization in the room 
to fit the standard; at the end of the learning activity, there is reflection and discussion (Hegde \& Meera, 2012). The last student takes the posttest for 20 minutes.

Modelling and simulation in this research will use MATLAB as its primary tool by using a second-order model to model the elements in the building and its thermal system. To analyze the results of modelling and simulation of energy consumption by the thermal system of a residence that is using MATLAB.

Simulink Block, which is a modelling of a room conditioning system, will follow the following conditions (Kassas, 2015).

\section{Set point}

"Set Point" is a representation as a block of constants. This block shows the temperature that must maintain the temperature in the room. In the simulation, the temperature score will adjust to the standard based on Governor Regulation No. $38 / 2012$ that is the minimum room temperature of $25^{\circ} \mathrm{C}$.

\section{Thermostat}

"Thermostat" is a subsystem consisting of a relay block. The thermostat functions as a sensor and controller located in the room. This block will allow fluctuations of $2{ }^{\circ} \mathrm{C}$ above or below the desired temperature.

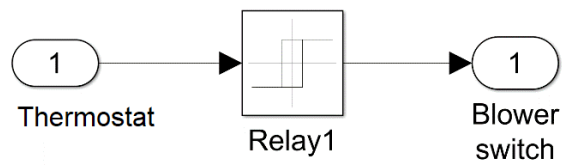

Figure 1. Block Modelling Results Controller Sub-system

$\mathrm{AC}$

"AC" is a subsystem that has a constant airflow rate, "Mdot." This AC block will work according to the command from the thermostat block, which will give a signal to turn on or turn off the AC. The on/off the cycle of the AC is to determine the predicted cooling cost of the cooling system on the model (Kassas, 2015).

The heat flowing from the air conditioner to the building according to the following equation.

$$
\frac{d Q_{A C}}{d t}=\left(T_{\text {cooler }}-T_{\text {room }}\right) * M_{\text {dot }} * C
$$

$\frac{d Q_{A C}}{d t}=$ cooling heat flow from the air conditioner to the room

Based on equation (1) and the block diagram in figure 1 it will form a Simulink block as follows (Figure 2):

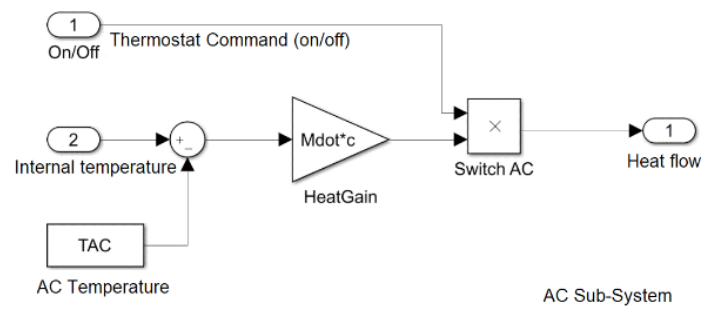

Figure 2. AC Subsystem Block Modelling Results

\section{Cooling costs}

It is a Gain block. This block integrates the AC work cycle over time. It multiplies it with the total electrical energy input from the cooling system according to the brand and type of air conditioner used and the score of the electricity cost per kWh (Yang et al., 2017). The cost of the thermal system is then plotted on "Cooling Costs".

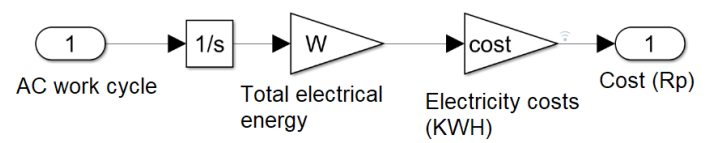

Figure 3. AC Subsystem Block Modelling Results

\section{Buildings}

"Building" is a sub-system that calculates the temperature difference in a room. In Figure 4, this sub-system takes into account the heat flow of the AC and the cooling load by the environment (Ardabili et al., 2016), based on the following equations.

$$
\begin{gathered}
\frac{d Q_{\text {load }}}{d t}=\frac{T_{\text {out }}-T_{\text {room }}}{R_{\text {eq }}} \\
\frac{d T_{\text {room }}}{d t}=\frac{1}{M_{\text {air }} * c} *\left(\frac{d Q_{A C}}{d t}-\frac{d Q_{\text {load }}}{d t}-\frac{d Q_{\text {people }}}{d t}\right)
\end{gathered}
$$

\section{Environmental Modelling}

The object of the building is the National University Physics Engineering Laboratory located on Bambu Kuning street, Pasar Minggu, South Jakarta. The building has a room temperature ranging from $25-31^{\circ} \mathrm{C}$ using a SANFIX TH308A temperature sensor. 
In Figure 4, it shows that the sub-system takes into account the heat flow of the AC and the cooling load by the environment (Ardabili et al., 2016), based on the equations (2) dan (3).

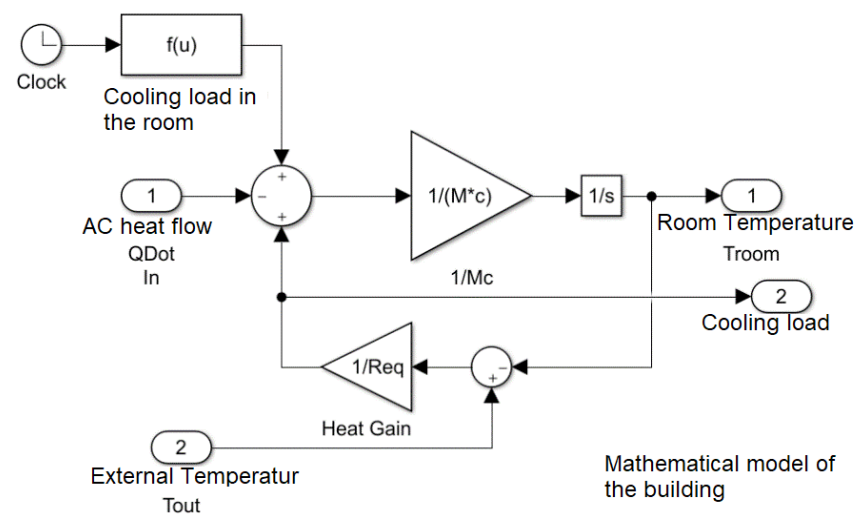

Figure 4. Block Building Sub-system Modelling Results

Futhermore, the environment as a crosssection of heat with unlimited heat capacity, and the temperature that affects it is Tout. See Figure 5 for Overall Thermal System Modelling Results.
Figure 5 is Environmental Modelling for Overall Thermal System Modelling Results. The object of the building is the National University Physics Engineering Laboratory.

\section{Building Thermal Models}

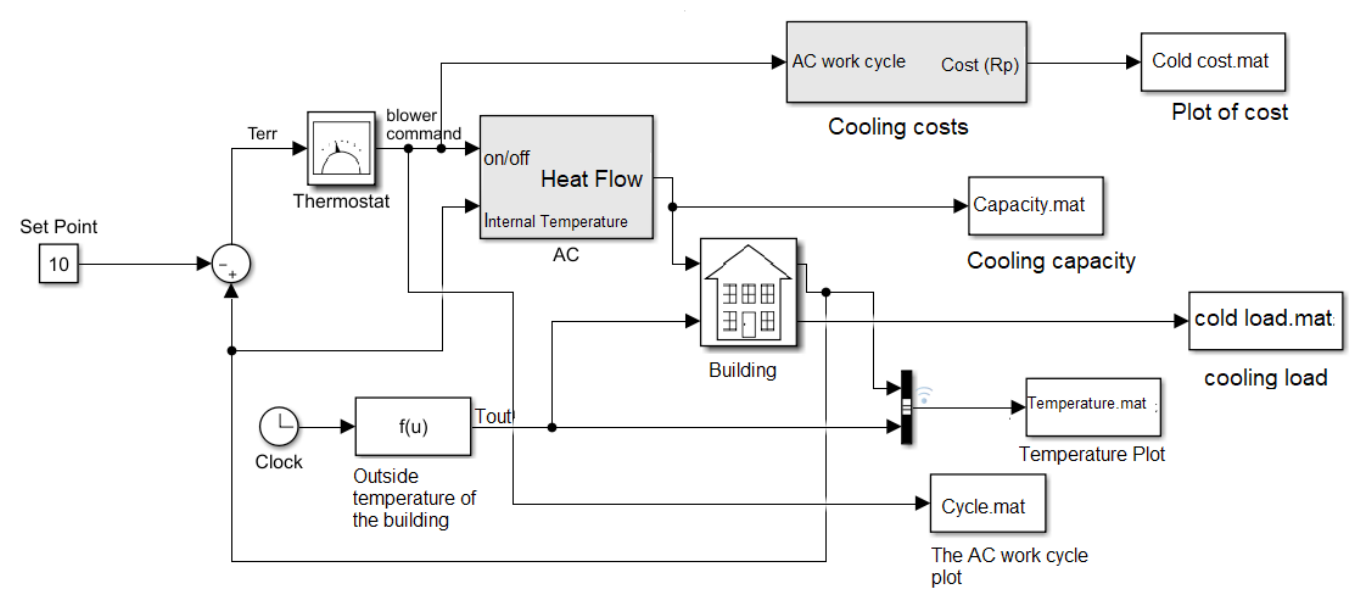

Figure 5. Overall Thermal System Modelling Results

The room (see Figure 6.) marked 'o' is the room that will be air-conditioned, while the room marked ' $\mathbf{x}$ ' is a passive room that is not airconditioned. The place marked 'o' will then be calculated the total mass of air inside it and will be modeled on the building block in the Simulink model. Students take measurements and simulation steps as in the modelling conditioning simulation thermal conditioning sub-chapter. 

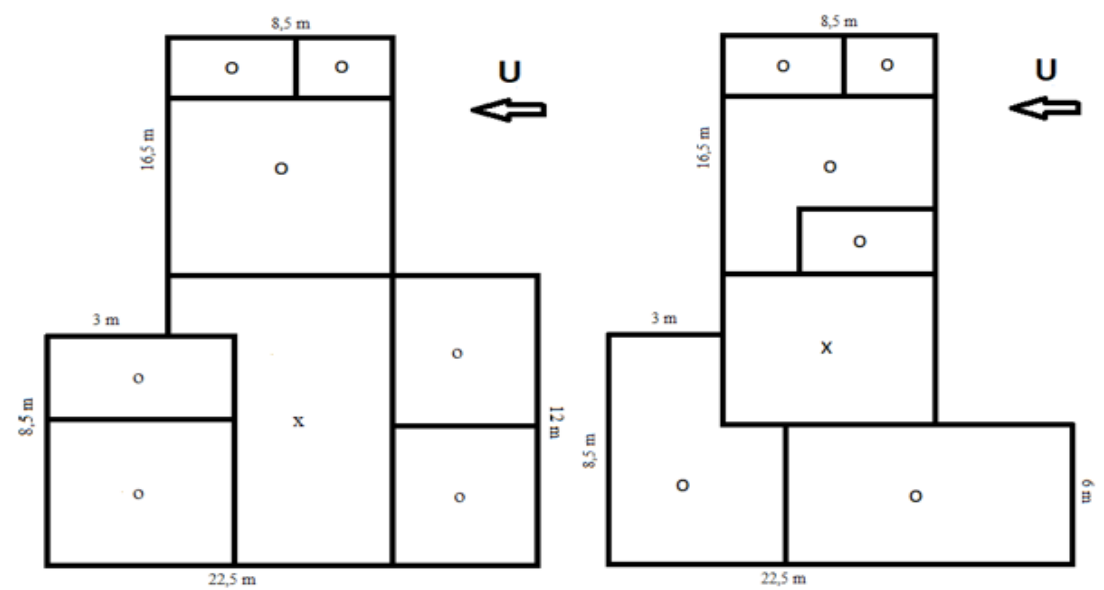

Figure 6. Floor Plans Building 1 and 2 Floor

\section{RESULTS AND DISCUSSION}

\section{Modelling and Simulation Testing}

The simulation results from modelling the thermal system in buildings by running the model on MATLAB Simulink produce the following graphs.

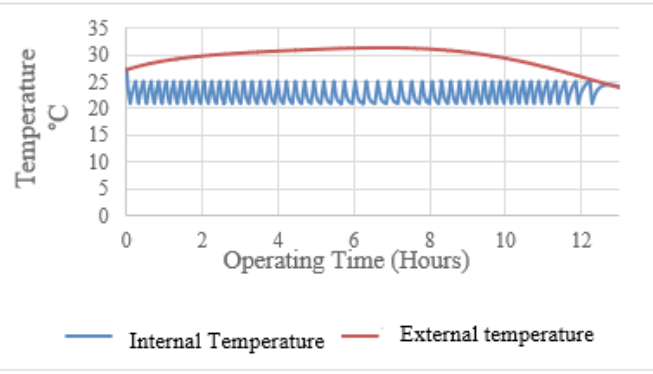

Figure 7. Comparison Between Room Temperature and Environmental Temperature

Figure 7 shows that the thermal system has succeeded in carrying out air conditioning from indoor temperatures during the building's operational time (08.00 - 20.00 WIB). The picture shows that the temperature in the room is in the range of $21-25^{\circ} \mathrm{C}$. Another parameter that indicates the model works well is that the temperature in the room will go down in more time when the temperature of the room is near the top. The picture shows that the model works according to these parameters. So, modelling in research goes well and can be applied in other buildings.

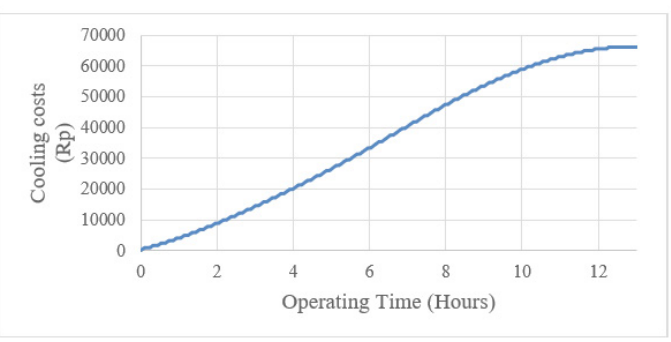

Figure 8. Accumulated Cooling Costs

The prediction of air conditioning costs in Figure 9 is Rp.665.947,00. This is the accumulation of one day's working air conditioning thermal system.

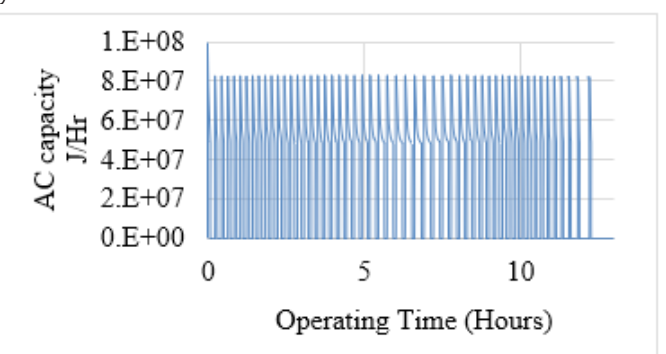

Figure 9. Building Cooling System Capacity Graph

The cooling capacity of the AC in Figure 9 is the optimum AC capacity that conducts air conditioning in the range of 21-25 degrees Celsius. This score has an error derived from assumptions when building the thermal system model. 
Based on the peak score of the graph in Figure 4.6 , the cooling capacity to optimize building comfort is $8 \times 107 \mathrm{~J} / \mathrm{h}$ or $22.22 \mathrm{~kW}$.

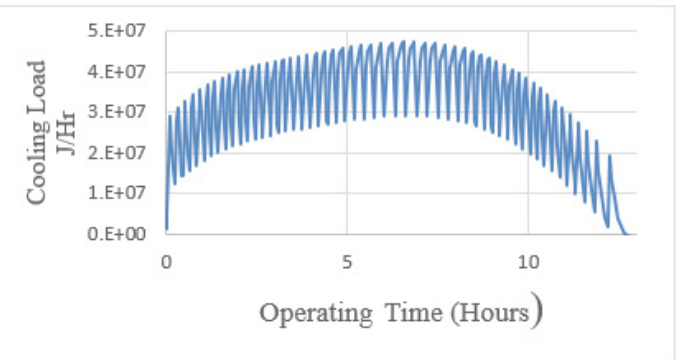

Figure 10. Graph of Cooling Loads Over Time

Figures 10 and 11 have a relationship between one another. From the two figures, it appears that when the cooling load approaches the peak temperature, the air conditioning thermal system will work longer. This also shows that the thermal system produced is functioning correctly.

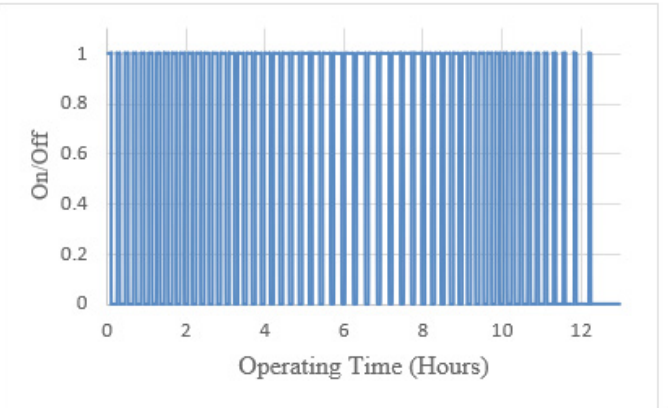

Figure 11. AC Work Cycle During Operating Time

The object of the building that has been simulated is the National University Physical Engineering Laboratory, obtaining a cooling capacity score to optimize the comfort of the building, which is $8 \times 107 \mathrm{~J} / \mathrm{h}$ or $22.22 \mathrm{~kW}$. While the cooling system already available in the building, according to table 4.7 is worth $12.54 \mathrm{~kW}$, so it requires an additional cooling system of $9.68 \mathrm{~kW}$. If the extra capacity of the cooling system will use the same branded air conditioner, then two pieces of DAIKIN-R35HEV1 air conditioner and 1 DAIKIN-R25HEV1 air conditioner are needed so that the indoor temperature is by the standards set by the Provincial Government of DKI Jakarta.

Based on the electrical energy input scores and the non-subsidized per-kWh electricity cost, and assuming the AC is running continuously because the indoor temperature does not reach the set point score. The cooling costs of the building can be determined before optimizing comfort building, namely:

$$
\begin{gathered}
\text { Cost }=((1,09 * 2)+(0,69 * 2)) * 12 * 1467,28 \\
=R p 62.682,00
\end{gathered}
$$

This score is not much different from the prediction of the air conditioning costs obtained based on the simulation seen in Figure 9, which is around IDR 66.5947,00. The difference in daily electricity costs is known to require an additional fee of IDR 3.265.00, or every month an additional charge of IDR 97.950.00 is needed. Another consideration that is taken into account in optimizing the comfort of buildings in the National University Physical Engineering Laboratory is the cost of purchasing additional air conditioners, in this case, in the form of 2 other DAIKIN-R35HEV1 air conditioners and 1 DAIKIN-R25HEV1 air conditioner.

The results of the study indicate that the simulation can be used for learning media. Thus, the simulation will be tested on physics engineering students who take building physics course.

\section{Simulation Learning Application}

After the models and simulations of instructional media are designed and can be appropriately used, the next step is a simulation application to support the learning process of students in the Building Physics course.

The assessment is carried out on test scores and assignment scores (Gibson et al., 2014). Test scores are done twice, namely pretest, for learning outcomes before using simulation media, and posttest: for learning outcomes after using simulation media (Ibáñez et al., 2016; Vidergor, 2018). The assignment score is also carried out twice, namely, task 1: assignments given before students learn to use simulation media, and Task 2 is an assignment (Worsley \& Blikstein, 2014). After students learn using simulation media (Figure 11) and Figure 12 is the result of the assessment in the pretest and posttest. Pretest, the average student pretest score was 70.27 , and the posttest score was 80.55 .

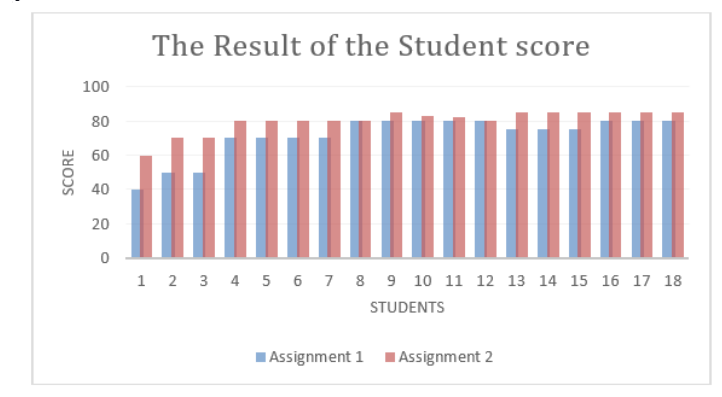

Figure 12. The Result of the Student's Score (Assignment) 
This shows an increase in cognitive learning outcomes in physics engineering students after using learning media in building physics course. Figure is the result of the assessment in task 1 (before using learning media) and Task 2 (after using learning media). The mean score for assignment 1 was 71.3 and assignment 2 was 80 .

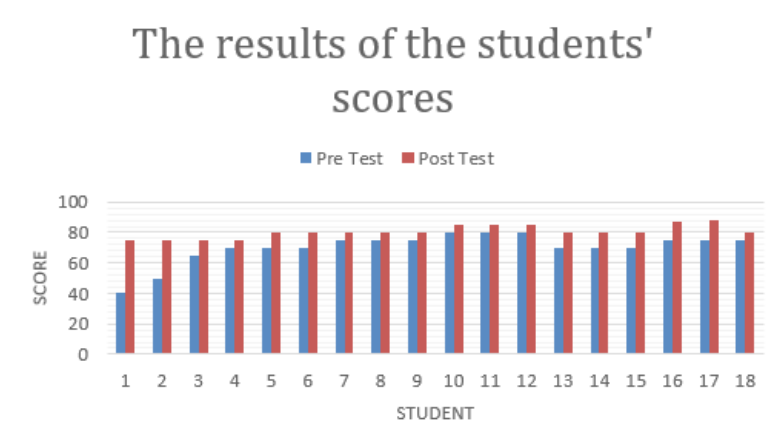

Figure 13. The Result of the Student's Score (Test)

Based on student scores obtained at the pretest, assignment 1 , assignment 2 , and posttest showed that there was an increase of $14.6 \%$ for

the Student Examination Score, while for the assignment score, there was an increase of $12.20 \%$. in detail shown in figure 14.

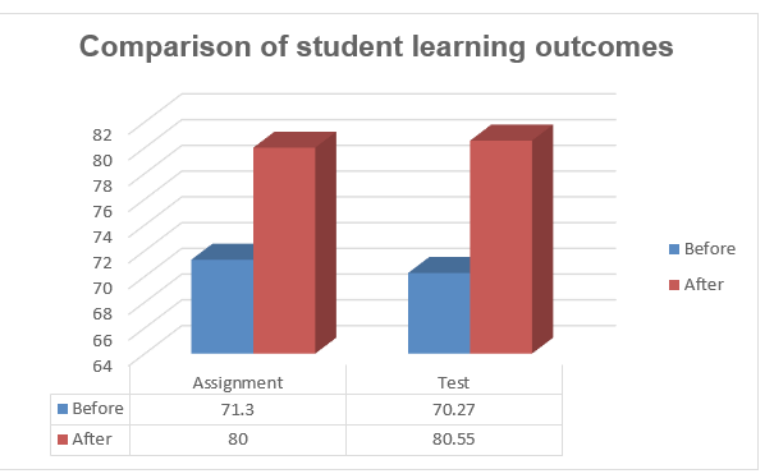

Figure 14. Improved Student Learning Outcomes

Based on the results of the research showed an increase in the percentage of student test results by $14.6 \%$ proving that simulation-based learning media can help improve student learning (Batlolona et al., 2018; Prima et al., 2018). Meanwhile, the percentage increase in the score of student assignments by $14.6 \%$ shows they are more productive in carrying out their jobs (Al-Hmouz et al., 2012). By applying studentcentered learning methods and using problembased learning and always providing support to students in the form of; stimulate students to find their problems and solutions so that this activity makes students focus on the learning process. Thus the challenges faced in the study of Schneider et al. (2010) can be overcome correctly.

To find out whether there are differences in student learning outcomes before and after using simulation-based learning media, it requires a paired sample T-test (Scheffel et al., 2015). The results are as follows.

Table 1. T-test Results for the Pretest and Posttest

\begin{tabular}{|c|c|c|c|c|c|c|c|c|c|}
\hline \multicolumn{10}{|c|}{ Paired Differences } \\
\hline & & \multirow[b]{2}{*}{ Mean } & \multirow{2}{*}{$\begin{array}{c}\text { Std. } \\
\text { Devia- } \\
\text { tion }\end{array}$} & \multirow{2}{*}{$\begin{array}{l}\text { Std. Er- } \\
\text { ror Mean }\end{array}$} & \multicolumn{2}{|c|}{$\begin{array}{l}95 \% \text { Confidence Inter- } \\
\text { val of the Difference }\end{array}$} & \multirow[b]{2}{*}{$\mathbf{t}$} & \multirow[b]{2}{*}{ df } & \multirow[t]{2}{*}{$\begin{array}{c}\text { Sig. } \\
\text { (2-tailed) }\end{array}$} \\
\hline & & & & & Lower & Upper & & & \\
\hline Pair 1 & $\begin{array}{l}\text { Pretest- } \\
\text { Posttest }\end{array}$ & -10.00000 & 8.18176 & 1.92846 & -14.06869 & -5.93131 & -5.185 & 17 & .000 \\
\hline
\end{tabular}


Based on Table 1 -t count $<-t$ table $(-5.18$ $<-2.11)$ and significance $<0.05(0.000<0.05)$, it can be concluded that there are differences in student test scores between before and after using

Table 2. T-test Results for the Assignment 1 and 2 simulation as a learning medium in the subject building physics. While for the test results on the assignment scores before and after using learningmedia are shown in Table 2.

\begin{tabular}{|c|c|c|c|c|c|c|c|c|c|}
\hline \multicolumn{10}{|c|}{ Paired Differences } \\
\hline & & \multirow[b]{2}{*}{ Mean } & \multirow{2}{*}{$\begin{array}{l}\text { Std. De- } \\
\text { viation }\end{array}$} & \multirow{2}{*}{$\begin{array}{l}\text { Std. } \\
\text { Error } \\
\text { Mean }\end{array}$} & \multicolumn{2}{|c|}{$\begin{array}{c}95 \% \text { Confidence } \\
\text { Interval of the Dif- } \\
\text { ference }\end{array}$} & \multirow[b]{2}{*}{$\mathbf{t}$} & \multirow[b]{2}{*}{ df } & \multirow[t]{2}{*}{$\begin{array}{c}\text { Sig. } \\
\text { (2-tailed) }\end{array}$} \\
\hline & & & & & Lower & Upper & & & \\
\hline Pair 1 & $\begin{array}{c}\text { Assignment1- } \\
\text { Assignment2 }\end{array}$ & -8.61111 & 6.31654 & 1.48882 & -11.75225 & -5.46997 & -5.784 & 17 & .000 \\
\hline
\end{tabular}

Based on table 2, t-count $<$ t-table $(-5.78$ $<-2.11)$ and significance $<0.05(0.000<0.05)$, it can be concluded that there are differences in the score of student assignments one between before and job 2 after using simulation as a learning media in the eyes college of building physics (Worsley \& Blikstein, 2014).

\section{CONCLUSION}

Based on the results of the discussion, it can be concluded that there is an increase in student learning outcomes in building physics course by using thermal comfort modelling and simulations of buildings. Hypothesis test results on both variables also showed t-count $<\mathrm{t}$-table and significance $<0.05$. This means that there are significant differences between pretest and posttest through the application of learning by simulation and using the SCL problem-based learning method (Luckin et al., 2015). Thus, this can be recommended to improve student learning outcomes on test scores and assignment scores. Further research is expected to look at other aspects such as students' conceptual changes (mental models), creativity and critical thinking related to learning building physics by using simulation media.

\section{REFERENCES}

Ahonen, A. K., Häkkinen, P., \& Pöysä-Tarhonen, J. (2018). Collaborative problem solving in Finnish pre-service teacher education: A case study. In Assessment and Teaching of 21st Century Skills (pp. 119-130). Springer, Cham.

Al-Hmouz, A., Shen, J., Al-Hmouz, R., \& Yan, J. (2012). Modeling and Simulation of an Adaptive Neuro-Fuzzy Inference System (ANFIS) for Mobile Learning. IEEE Transactions on Learning Technologies, 5(3), 226-237.

Ardabili, S. F., Mahmoudi, A., \& Gundoshmian, T. M. (2016). Modeling and simulation controlling system of HVAC using fuzzy and predictive (radial basis function, RBF) controllers. Journal of Building Engineering, 6, 301-308.

Aryuntini, N., Astuti, I., \& Yuliana, Y. (2018). Development of Learning Media Based on VideoScribe to Improve Writing Skill for Descriptive Text of English Language Study. Journal of Education, Teaching and Learning, 3(2), 187-194.

Batlolona, J. R., Baskar, C., Kurnaz, M. A., \& Leasa, M. (2018). The improvement of problem-solving skills and physics concept mastery on temperature and heat topic. Jurnal Pendidikan IPA Indonesia, 7(3), 273-279.

Bronack, S. C. (2011). The role of immersive media in online education. The Journal of Continuing Higher Education, 59(2), 113-117.

Budaiwi, I., \& Abdou, A. (2013). HVAC system operational strategies for reduced energy consumption in buildings with intermittent occupancy: The case of mosques. Energy conversion and management, 73, 37-50.

Chen, Y., \& Treado, S. (2014). Development of a simulation platform based on dynamic models for HVAC control analysis. Energy and Buildings, 68, 376-386.

Cheng, K. H., \& Tsai, C. C. (2013). Affordances of augmented reality in science learning: Suggestions for future research. Journal of science education and technology, 22(4), 449-462.

Cukurova, M., Avramides, K., Spikol, D., Luckin, R., \& Mavrikis, M. (2016, April). An analysis framework for collaborative problem solving in practice-based learning activities: a mixedmethod approach. In Proceedings of the Sixth International Conference on Learning Analytics \& Knowledge (pp. 84-88).

De Jong, T., Linn, M. C., \& Zacharia, Z. C. (2013). Physical and virtual laboratories in science and engineering education. Science, 340(6130), 305308.

Dunn, A. M., Hofmann, O. S., Waters, B., \& Witchel, E. (2011, August). Cloaking Malware with the Trusted Platform Module. In USENIX Security Symposium. 
Gibson, A., Kitto, K., \& Willis, J. (2014, March). A cognitive processing framework for learning analytics. In Proceedings of the fourth international conference on learning analytics and knowledge (pp. 212-216).

Greiff, S., Wüstenberg, S., Csapó, B., Demetriou, A., Hautamäki, J., Graesser, A. C., \& Martin, R. (2014). Domain-general problem solving skills and education in the 21st century. Educational Research Review, (13), 74-83.

Guillaud, X., Faruque, M. O., Teninge, A., Hariri, A. H., Vanfretti, L., Paolone, M., Dinavahi, V., Mitra, P., Lauss, G., Dufour, C., Forsyth, P., Srivastava, A. K., Strunz, K., Strasser, T., \& Davoudi, A. (2015). Applications of Real-Time Simulation Technologies in Power and Energy Systems. IEEE Power and Energy Technology Systems Journal, 2(3), 103-115.

Hegde, B., \& Meera, B. N. (2012). How do they solve it? An insight into the learner's approach to the mechanism of physics problem solving. Physical Review Special Topics-Physics Education Research, 8(1), 010109.

Ibanez, M. B., Di-Serio, A., Villaran-Molina, D., \& Delgado-Kloos, C. (2016). Support for Augmented Reality Simulation Systems: The Effects of Scaffolding on Learning Outcomes and Behavior Patterns. IEEE Transactions on Learning Technologies, 9(1), 46-56.

Jaakkola, T., Nurmi, S., \& Veermans, K. (2011). A comparison of students' conceptual understanding of electric circuits in simulation only and simulation-laboratory contexts. Journal of research in science teaching, 48(1), 71-93.

Johnson, L., Smith, R., Willis, H., Levine, A., \& Haywood, K. (2011). The 2011 Horizon Report. New Media Consortium.

Kassas, M. (2015). Modeling and Simulation of Residential HVAC Systems Energy Consumption. Procedia Computer Science, 52, 754-763.

Luckin, R., Mavrikis, M., Avramides, K., \& Cukurova, M. (2015, January). Analysing Project Based Learning Scenarios to Inform the Design of Learning Analytics: Learning from Related Concepts. In AIED Workshops.
Prima, E. C., Putri, A. R., \& Rustaman, N. (2018). Learning Solar System Using PhET Simulation to Improve Students' Understanding and Motivation. Journal of Science Learning, 1(2), 60-70.

Requena-Carrión, J., Alonso-Atienza, F., GuerreroCurieses, A., \& Rodríguez-González, A. B. (2010, April). A student-centered collaborative learning environment for developing communication skills in engineering education. In IEEE EDUCON 2010 Conference (pp. 783-786). IEEE.

Scheffel, M., Drachsler, H., \& Specht, M. (2015, March). Developing an evaluation framework of quality indicators for learning analytics. In Proceedings of the Fifth International Conference on Learning Analytics And Knowledge (pp. 16-20).

Schneider, B., Jermann, P., Zufferey, G., \& Dillenbourg, P. (2010). Benefits of a tangible interface for collaborative learning and interaction. IEEE Transactions on Learning Technologies, 4(3), 222232.

Smetana, L. K., \& Bell, R. L. (2012). Computer simulations to support science instruction and learning: A critical review of the literature. International Journal of Science Education, 34(9), 1337-1370.

Vidergor, H. E. (2018). Effectiveness of the multidimensional curriculum model in developing higher-order thinking skills in elementary and secondary students. The Curriculum Journal, 29(1), 95-115.

Wang, Y., Kuckelkorn, J., Zhao, F. Y., Liu, D., Kirschbaum, A., \& Zhang, J. L. (2015). Evaluation on classroom thermal comfort and energy performance of passive school building by optimizing HVAC control systems. Building and Environment, 89, 86-106.

Worsley, M., \& Blikstein, P. (2014). Analyzing engineering design through the lens of computation. Journal of Learning Analytics, 1(2), 151-186.

Yang, Y., Wang, B., \& Zhou, Q. (2017). Air Conditioning System Design using Free Cooling Technology and Running Mode of a Data Center in Jinan. Procedia Engineering, 205, 3545-3549. 